\title{
Short Communication Adiponectin gene and risk of colorectal cancer
}

\author{
MC Gornick', G Rennert ${ }^{2}$, V Moreno ${ }^{3}$ and SB Gruber*,1,4,5 \\ 'Department of Human Genetics, University of Michigan School of Medicine, 1524 BSRB, 109 Zina Pitcher, Ann Arbor, MI, USA; ${ }^{2}$ Department of \\ Community Medicine and Epidemiology, Clalit Health Service National Cancer Control Center, Carmel Medical Center and B. Rappaport Faculty of \\ Medicine, Technion-Israel Institute of Technology, Haifa, Israel; ${ }^{3}$ Institut Català d'Oncologia (ICO), IDIBELL, CIBER-ESP, L'Hospitalet de Llobregat, Spain; \\ ${ }^{4}$ Department of Internal Medicine, University of Michigan School of Medicine, 1524 BSRB, 109 Zina Pitcher, Ann Arbor, MI, USA; ${ }^{5}$ eepartment of \\ Epidemiology, University of Michigan School of Public Health, 1524 BSRB, 109 Zina Pitcher, Ann Arbor, MI, USA
}

BACKGROUND: Genes of the adiponectin pathway are interesting candidates for colorectal cancer risk based on the potential association between colorectal cancer and obesity. However, variants of the adiponectin gene (ADIPOQ) have been demonstrated to be inconsistently associated with risk of colorectal cancer.

METHODS: The current study attempted to evaluate these findings by examining several single nucleotide polymorphisms (SNPs) that were previously genotyped as part of a genome-wide association study in the ADIPOQ gene. Genotyping was also performed for a previously reported risk variant, rs266729, in 1062 individuals with a diagnosis of colorectal cancer and 1062 controls matched on age, gender and ethnicity (Jewish or not Jewish) as part of a population-based case-control study in Israel.

RESULTS: No evidence was found for an association between ADIPOQ and risk of colorectal cancer. The single nucleotide variant previously associated with decreased risk of colorectal cancer, rs266729, revealed an adjusted odds ratio of 1.04 ; $95 \%$ confidence interval, $0.88-1.23$.

CONCLUSION: The SNP, rs266729, was not strongly associated with colorectal cancer in patients of Ashkenazi Jewish descent or other ethnic groups in Israel.

British Journal of Cancer (20II) I 05, 562-564. doi:I0.1038/bjc.20II.259 www.bjcancer.com

(C) 2011 Cancer Research UK

Keywords: adiponectin; ADIPOQ; colorectal cancer

Decreased levels of circulating adiponectin, a hormone secreted by the adipose tissue, have been found to be directly associated with obesity and hyperinsulinemia (Vona-Davis et al, 2007). The combination of the association of adiponectin with insulin resistance, support for an association of obesity with risk of colorectal cancer, and a previous report which found that adiponectin levels were inversely associated with risk of colorectal cancer suggest that the adiponectin pathway may contribute to colorectal carcinogenesis (Wei et al, 2005; Moghaddam et al, 2007; Vona-Davis et al, 2007; Fenton et al, 2008; Williams et al, 2008). An association between genes of the adiponectin pathway and risk of colorectal cancer was recently reported in a multicenter casecontrol study (Kaklamani et al, 2008). Kaklamani et al identified a single nucleotide polymorphism (SNP, rs266729) in the adiponectin gene $(A D I P O Q)$ that was associated with decreased risk of colorectal cancer. However, subsequent reports did not validate the findings of Kaklamani (Carvajal-Carmona et al, 2009; Pechlivanis et al, 2009). In response to this intriguing hypothesis and inconsistent data, we examined several SNPs in the ADIPOQ gene that were genotyped as part of an ongoing genome-wide association study (GWAS) (Gruber et al, 2007). We also specifically genotyped the variant rs266729 in 1062 colorectal cancer cases and 1062 matched controls.

*Correspondence: Dr SB Gruber; E-mail: sgruber@umich.edu Received I4 March 20 II; revised I4 June 20 II; accepted I6 June 20 I I

\section{MATERIALS AND METHODS}

Histopathologically confirmed cases of all incident colorectal cancer diagnosed in northern Israel between 31 March 1998 and 31 March 2004 were recruited as part of the Molecular Epidemiology of Colorectal Cancer study. Population-based controls were identified from the Clalit Health Service database and matched to cases by year of birth, gender, clinic and Jewish/Arab ethnicity (Poynter et al, 2005). The study was approved by all relevant IRBs in the US and Israel, and written informed consent was given by study participants. SNPs within $A D I P O Q$ were analysed as part of our GWAS to test the hypothesis that SNPs in linkage disequilibrium with the published risk variants of $A D I P O Q$ were associated with risk (Table 1). Stage 1 of our GWAS (Gruber et al, 2007) used pooled DNA of cases $(n=500)$ and pooled DNA of controls $(n=500)$. Standard errors used for $t$-tests of pooled allele frequencies were corrected by adding a chip-specific constant to avoid biased selection of SNPs with small standard errors (Table 2b).

Our subsequent validation analysis had $95 \%$ power to detect an odds ratio (OR) of 0.73 by individually genotyping genomic DNA from 1062 matched pairs using Taqman SNP allelic discrimination (Table 1). Less than $5 \%$ of genotypes were scored as equivocal and $1 \%$ of the sample was genotyped in duplicate with $100 \%$ concordance. Conditional logistic regression was used to calculate ORs in R (version 2.11.1, R Development Core Team, http://www. R-project.org) and SAS (version 9.1, SAS Institute Inc., Cary, NC, USA). Analyses were adjusted for ethnicity (Ashkenazi Jewish, Sephardi Jewish, Arab) and APC I1307K. 
Table I Study characteristics of GWAS and validation sample

\begin{tabular}{lcc}
\hline & Cases* & Controls* \\
\hline Pooled GWAS sample & & \\
Age (years) & $69.9($ s.d. $=11.7)$ & $70.0($ s.d. $=11.7)$ \\
\% Ashkenazi & $100 \%$ & $100 \%$ \\
\% Male & $51 \%$ & $50 \%$ \\
Validation sample & & \\
Age (years) & & \\
\% Ashkenazi & $70.1($ s.d. $=11.5)$ & $71.1($ s.d. $=11.5)$ \\
\% Male & $90 \%$ & $90 \%$ \\
\hline
\end{tabular}

Abbreviation: GWAS = genome-wide association study. *The participation rate was $67.5 \%$ among eligible cases and $52.1 \%$ of eligible controls. Participating cases were slightly younger (mean 70.1 years) than cases who declined (mean 70.4 years), whereas those who could not participate because they were too ill or died were significantly older (mean 78.9 years).

Table 2a ADIPOQ allele frequencies in DNA pools of 500 Ashkenazi Jewish cases and 500 Ashkenazi Jewish controls from GWAS

\begin{tabular}{llccccc}
\hline & & $\begin{array}{c}\text { Allele } \\
\text { frequency } \\
\text { in cases }\end{array}$ & $\begin{array}{c}\text { Allele } \\
\text { frequency } \\
\text { in } \\
\text { controls }\end{array}$ & $\begin{array}{c}\text { Allele } \\
\text { frequency } \\
\text { difference } \\
\text { (delta phat) }\end{array}$ & $\begin{array}{c}\text { Uncorrected } \\
\text { P-values }\end{array}$ & P-value $^{\mathbf{a}}$ \\
\hline rs16861194 & - & $0.8237 \mid 3$ & 0.827086 & -0.00337 & 0.91 & 0.94 \\
rs182052 & 0.12 & 0.351247 & 0.347727 & 0.00352 & 0.75 & 0.87 \\
rs822395 & NA & 0.332435 & 0.359826 & -0.02739 & 0.43 & 0.54 \\
rs3821799 & 0.15 & 0.725486 & 0.727804 & -0.00232 & 0.93 & 0.95 \\
rs6773957 & 0.78 & 0.420488 & 0.411588 & 0.00890 & 0.66 & 0.77 \\
rs1063537 & 0.21 & 0.814909 & 0.768118 & 0.04679 & 0.03 & 0.12 \\
rs2082940 & 1.00 & 0.103103 & 0.133517 & -0.03041 & 0.11 & 0.30 \\
\hline
\end{tabular}

Abbreviations: GWAS = genome-wide association study; NA = non-applicable; $\mathrm{SNP}=$ single nucleotide polymorphism. ${ }^{\text {a }} P$-values derived from corrected $t$-test using a constant to correct the allele frequency difference. $P$-values are not adjusted for multiple comparisons. Note that the highest $r^{2}$ value between rs266729 and any of the SNPs included in the GWAS study is 0.74 (rs|82052).

\section{RESULTS}

Our GWAS study did not identify a significant association between any of the genotyped SNPs in the ADIPOQ gene and risk of colorectal cancer (Table 2a). Using the dominant model to replicate Kaklamani's reported findings, SNP rs266729 revealed an adjusted OR (adjusted for age, gender, ethnicity and $A P C I 1307 \mathrm{~K}$ status) of $1.04 ; 95 \%$ confidence interval $(95 \% \mathrm{CI}), 0.88-1.23$. The OR among Ashkenazi Jews only was 1.01 (95\% CI $0.82-1.24$ ). Excluding overlapping cases and controls used in both the initial pooled GWAS analysis and the individual genotyping of the subsequent validation study yielded an adjusted $\mathrm{OR}=1.12,95 \% \mathrm{CI}$ $(0.91,1.38)$. The SNP rs266729 was in Hardy-Weinberg equilibrium in the controls. The prevalence of the CC genotype differed between the current study and the report by Kaklamani (55 vs $51 \%$, $P$-value $=0.02478)$. Therefore, we compared the MECC cases to the
Table 2b ADIPOQ SNP rs266729 genotypes in the MECC study

\begin{tabular}{ccccc}
\hline Genotypes & Controls & Cases & OR (95\% CI) & P-value \\
\hline Total sample & 1062 & 1062 & & \\
CC & 588 & 576 & 1.00 (Reference) & \\
CG/GG & 474 & 486 & $1.04(0.88-1.23)$ & 0.66 \\
Ashkenazi Jews & 672 & 741 & & \\
CC & 365 & 400 & 1.00 (Reference) & \\
CG/GG & 307 & 341 & 1.01 (0.82-1.24) & 0.98 \\
Sephardi Jews & 267 & 191 & & \\
CC & 154 & 103 & 1.00 (Reference) & \\
CG/GG & 113 & 88 & 1.18 (0.81-1.73) & 0.38 \\
Arab & & & & \\
CC & 106 & 111 & & \\
CG/GG & 59 & 63 & 1.00 (Reference) & \\
\hline
\end{tabular}

Abbreviations: $\mathrm{Cl}=$ confidence interval; $\mathrm{OR}=$ odds ratio; $\mathrm{SNP}=$ single nucleotide polymorphism. ${ }^{a}$ Adjusted for ethnicity and APC II307K status.

combined control group of Kaklamani et al and calculated an $\mathrm{OR}=1.10,95 \%$ CI $(0.92,1.32)$. Based on the current data we conclude that rs266729 in $A D I P O Q$ is not associated with risk of colorectal cancer in a comparable population-based sample.

\section{CONCLUSION}

In contrast to one previous publication (Kaklamani et al, 2008) but consistent with two others (Carvajal-Carmona et al, 2009; Pechlivanis et al, 2009), we found no association with variants of $A D I P O Q$ and risk of colorectal cancer. It should be noted that in the study by Carvajal-Carmona, genotypes at rs266729 were imputed in the CORGI cohort, but confirmed the absence of association with CRC risk. Based on the results from the current study, rs266729 was not associated with colorectal cancer in patients of Ashkenazi Jewish descent or other ethnic groups in Israel. It seems likely that the original publication represents a 'winner's curse', or a chance observation in an initial study, as our larger, population-based study of the same ethnic group appears to be representative of the age and sex distribution of colorectal cancer among most western populations. Together with the data from the present study, a recent study by Pechlivanis et al reports that it is unlikely that genetic variation in $A D I P O Q$ confers risk of colorectal cancer. However, we cannot exclude a weak association particularly because some studies had shown a differential effect in populations from the United States $v s$ other European populations.

\section{ACKNOWLEDGEMENTS}

This work was funded by NCI R01-81488 and NCI 5 P30 CA46592.

\section{REFERENCES}

Carvajal-Carmona LG, Spain S, Kerr D, Houlston R, Cazier JB, Tomlinson I (2009) Common variation at the adiponectin locus is not associated with colorectal cancer risk in the UK. Hum Mol Genet 18: 1889-1892

Fenton JI, Birmingham JM, Hursting SD, Hord NG (2008) Adiponectin blocks multiple signaling cascades associated with leptin-induced cell proliferation in Apc Min/+ colon epithelial cells. Int J Cancer 122: $2437-2445$

Gruber SB, Moreno V, Rozek LS, Rennert HS, Lejbkowicz F, Bonner JD, Greenson JK, Giordano TJ, Fearon ER, Rennert G (2007) Genetic variation in 8q24 associated with risk of colorectal cancer. Cancer Biol Ther 6: 1143 - 1147

Kaklamani VG, Wisinski KB, Sadim M, Gulden C, Do A, Offit K, Baron JA, Ahsan H, Mantzoros C, Pasche B (2008) Variants of the adiponectin (ADIPOQ) and adiponectin receptor 1 (ADIPOR1) genes and colorectal cancer risk. JAMA 300: $1523-1531$

Moghaddam AA, Woodward M, Huxley R (2007) Obesity and risk of colorectal cancer: a meta-analysis of 31 studies with 70000 events. Cancer Epidemiol Biomarkers Prev 16: 2533 - 2547 
Pechlivanis S, Bermejo JL, Pardini B, Naccarati A, Vodickova L, Novotny J, Hemminki K, Vodicka P, Forsti A (2009) Genetic variation in adipokine genes and risk of colorectal cancer. Eur J Endocrinol 160: 933-940

Poynter JN, Gruber SB, Higgins PD, Almog R, Bonner JD, Rennert HS, Low $\mathrm{M}$, Greenson JK, Rennert G (2005) Statins and the risk of colorectal cancer. N Engl J Med 352: 2184-2192

Vona-Davis L, Howard-McNatt M, Rose DP (2007) Adiposity, type 2 diabetes and the metabolic syndrome in breast cancer. Obes Rev 8: 395-408

Wei EK, Giovannucci E, Fuchs CS, Willett WC, Mantzoros CS (2005) Low plasma adiponectin levels and risk of colorectal cancer in men: a prospective study. J Natl Cancer Inst 97: 1688-1694

Williams CJ, Mitsiades N, Sozopoulos E, Hsi A, Wolk A, Nifli AP, Tseleni-Balafouta S, Mantzoros CS (2008) Adiponectin receptor expression is elevated in colorectal carcinomas but not in gastrointestinal stromal tumors. Endocr Relat Cancer 15: $289-299$ 